\title{
COR TRIATRIUM
}

\author{
BY \\ N. R. BARRETT AND JOHN B. HICKIE \\ London \\ Sydney
}

Cor triatrium is a congenital malformation of the heart in which a transverse septum divides the left atrium into two chambers, separating the opening of the pulmonary veins from the mitral orifice. It is a rare cardiac anomaly. In an analysis of 1,000 necropsies of congenital heart disease Abbott (1946) found it seven times, although in 10 specimens anomalous cordae were present in the left atrium.

The condition was mentioned by Andral (1829), and described originally by Church (1868). The latter reported a woman of 38 years who died with pulmonary congestion and congestive cardiac failure, and necropsy revealed a membraneous septum stretched across the left atrium. Since then 23 cases have been described. Barnes and Finlay (1952) state that this septum "appears to be so eminently suitable for surgical treatment that every effort should be made to recognize the abnormality during life."

The following patient is interesting in that mitral valve disease was suggested by clinical and physiological studies, but the true diagnosis was made after cardiotomy, and subsequently a successful operation was performed. The pressures in the various cardiac chambers were recorded before and after division of the left atrial septum.

\section{CASE Report}

A man aged 17 years had mild exertional dyspnoea and bronchitis for many years, with increasing breathlessness and productive cough for two years. One week before his first admission he had an haemoptysis.

On examination he had a pigeon chest and a dorsal kyphosis. The pulse was regular, the blood pressure $110 / 60 \mathrm{~mm}$. $\mathrm{Hg}$, and the jugular venous pressure normal. There was no cardiac enlargement, but a right ventricular impulse was palpable. There was an accentuated split second sound at the base, a normal mitral first sound, no opening snap, and a grade one mitral diastolic murmur. In the electrocardiogram there was right ventricular hypertrophy and broad notched $P$ waves. Radiography showed enlarged pulmonary arteries, right ventricular enlargement, and no valve calcification. A diagnosis of mitral stenosis was made.

Six months later he had a further haemoptysis and was readmitted. The signs were unaltered except that the mitral diastolic murmur was heard with great difficulty and its presence doubted by most observers. Cardiac catheterization (Table I) showed pulmonary hypertension, an elevated "pulmonary capillary

TABLE I

RESULTS OF INITIAL CARDIAC CATHETERIZATION

\begin{tabular}{|c|c|c|c|c|c|}
\hline \multirow{2}{*}{\multicolumn{2}{|c|}{ Position }} & \multicolumn{3}{|c|}{ Pressures } & \multirow{2}{*}{$\begin{array}{c}\text { Oxygen } \\
\text { (vol.) }\end{array}$} \\
\hline & & Systolic & Diastolic & Mitral & \\
\hline $\begin{array}{l}\text { S.V.C. } \\
\text { R.A. } \\
\text { R.V. } \\
\text { P.A. } \\
\text { P.C. } \\
\text { P.C.E.X. } \\
\text { B.A. }\end{array}$ & $\begin{array}{l}\cdots \\
\cdots \\
\cdots \\
\cdots \\
\cdots\end{array}$ & $\begin{array}{l}\overline{5} \\
92 \\
92 \\
52 \\
\overline{110}\end{array}$ & $\begin{array}{l}-1 \cdot 5 \\
0 \\
62 \\
32 \\
\overline{60}\end{array}$ & $\begin{array}{r}-3 \\
50 \\
75 \\
40 \\
65 \\
\end{array}$ & $\begin{array}{c}13.5(65 \%) \\
13.1(63 \%) \\
13.2(63 \%) \\
14.4(69 \%) \\
- \\
19.8(95 \%)\end{array}$ \\
\hline
\end{tabular}

wedge pressure" with a rise on exercise, and no evidence of an intracardiac shunt. The form of the "pulmonary capillary wedge tracing" was consistent with tight mitral stenosis. As the diagnosis was doubtful, an angiocardiogram was attempted, but rapid auricular fibrillation developed early in the procedure and it had to be abandoned. Normal rhythm was restored with "digoxin" and quinidine. Oximetric studies following Valsalva's manœuvre, before and after exercise, showed no evidence of an atrial septal defect.

\section{Operative Findings}

The first thoracotomy was done without an accurate pre-operative diagnosis. The history and the physical signs were not typical of rheumatic heart disease, and it was upon probability that mitral stenosis was suggested as the most likely cause of the high pressure which was known to exist in the pulmonary vascular bed. This diagnosis was made in the absence of the typical murmurs, without evidence of left atrial enlargement, and without an opening snap.

The possibility that the obstruction in the atrium was caused by a myxoma, arising from the septum, was entertained, but was not considered to be probable.

We may wonder, in retrospect, if left atrial puncture done either at bronchoscopy or by direct needling, would have clarified the issue. If the catheter or needle had entered the upper chamber a high pressure (different from that of the pulmonary artery) would have been recorded; if it could then have been juggled through the orifice in the septum, which seems doubtful considering its position, an accurate diagnosis 
might have been made; in these circumstances there would have been a zone of high pressure, then one of normal pressure before the typical ventricular tracings were obtained. If, on the other hand, the needle had entered the lower chamber, normal atrial pressures would have been recorded and a diagnosis of primary pulmonary hypertension would have been suggested.

The left chest was opened as for a mitral valvotomy. The lung was congested and did not deflate easily. The heart appeared to be normal in size ; but the pulmonary artery was dilated and so were the left pulmonary veins. The pericardium was normal. The left atrium was enlarged and its upper surface was dark in colour and firm to palpation; the auricular appendage felt, and looked, normal ; a thrill was palpable at the top of the left atrium in the groove between it and the pulmonary artery. No anomalous vessels were seen.

The auricular appendage was opened in the usual way. It contained no clot and the mitral valve felt normal in anatomy and movement. Exploration of the atrium itself showed it to be unusual, but it was not obvious what the abnormality was. The lower part of the chamber presented nothing suspicious, but the upper two-thirds was tense. It felt as though this area were occupied by a large, soft, doughy " tumour," but this diagnosis was improbable because the exploring finger could not be passed to the top of the chamber. The lower surface of the "mass" was smooth and bulged downwards: it could be indented and compressed, but immediately regained its shape. On further palpation it became obvious that the lower surface was, in fact, a septum passing from a point just below the entry of the left pulmonary veins, across the chamber to the inner side of the atrium above the mitral ring. At this time the exploring finger unexpectedly entered a small defect in the abnormal septum: the aperture was about $1 \mathrm{~cm}$. by $\frac{1}{2} \mathrm{~cm}$. in extent and the margins were firm and contained prickly calcification. In retrospect it is surprising that this foramen was not discovered sooner, but it lay at some distance from the surface of the atrium. Not having the possibility of cor triatrium in mind, I (N. R. B.) assumed that the lesion was one in which the interatrial septum had grown in an unusual site and that a defect had persisted in it. Because of this opinion nothing further was done and the operation was concluded. Convalescence was uneventful.

TABLE II

RESULTS OF CARDIAC CATHETERIZATION BEFORE AND AFTER OPERATION

\begin{tabular}{|c|c|c|c|c|c|c|c|}
\hline \multirow{2}{*}{\multicolumn{2}{|c|}{ Position }} & \multicolumn{3}{|c|}{ Pressure Before Operation } & \multicolumn{3}{|c|}{ Pressure After Operation } \\
\hline & & Systolic & Diastolic & Mitral & Systolic & Diastolic & Mitral \\
\hline $\begin{array}{l}\text { L.V. } \\
\text { Aorta } \\
\text { P.A. } \\
\text { R.V. } \\
\text { L.A.1 } \\
\text { L.A. } 2\end{array}$ & $\begin{array}{l}\ldots \\
\ddot{0} \\
\cdots \\
\cdots\end{array}$ & $\begin{array}{l}87 \\
86 \\
65 \\
65 \\
- \\
-\end{array}$ & $\begin{array}{r}0 \\
58 \\
43 \\
0 \\
- \\
-\end{array}$ & $\begin{array}{l}\bar{Z} \\
\bar{Z} \\
22\end{array}$ & $\begin{array}{l}85 \\
83 \\
- \\
- \\
-\end{array}$ & $\begin{array}{r}0 \\
62 \\
- \\
- \\
-\end{array}$ & $\begin{array}{c}- \\
\bar{E} \\
5\end{array}$ \\
\hline
\end{tabular}

L.A.1 = antero-inferior chamber of left atrium. L.A. 2 = postero-superior chamber of left atrium.
On talking the matter over with a colleague at the Brompton Hospital (Dr. Gibson) the true diagnosis was suggested, and it was obvious that the findings at the first operation exactly fitted the bill. It should be emphasized that the pre-operative investigations had not shown evidence of an interatrial shunt, a fact which made the diagnosis of atrial septal defect extremely unlikely. In retrospect the writer would submit that a surgeon familiar with this deformity would have no difficulty in coming to a correct diagnosis at operation.

A second thoracotomy was done in March, 1956. The left atrium was explored and opened without difficulty. The diagnosis of cor triatrium was confirmed by palpation and by taking the pressures in the upper and lower chambers of the left atrium. The foramen in the septum was too tough to split or enlarge by finger fracture, but it was easily cut with a mitral knife. Once the edges of the hole had been incised the split in the septum was completed from one wall of the atrium to the other. There was no difficulty about the operation, although the possibility of dislodging a spicule of calcification into the systemic blood stream, and so of causing cerebral embolism, was ever present.

When the septum had been split there was no difference in pressure between the top and the bottom of the left atrium and the thrill had disappeared.

Convalescence was uneventful, and 10 months later the boy was normal in every way; he plays football with interest and efficiency, and says he has no symptoms.

\section{ANATOMY}

In this condition a transverse fibrous or fibromuscular septum divides the left atrium into two chambers, an upper or postero-superior one which receives the pulmonary veins and a lower or antero-inferior one which contains the orifice of the atrial appendix and the mitral opening (Palmer, 1930). The auricular appendix always opens into the lower chamber. The upper chamber is usually the larger and is often funnelor wedge-shaped. The membrane extends from the interatrial septum in the region of the foramen ovale to the antero-lateral wall of the atrium just below the left inferior pulmonary vein. It usually arises above the foramen ovale (Parsons, 1950), but may arise below it (Edwards, DuShane, Alcott, and Burchell, 1951) or at it, the medial edge of the septum dividing into two to enclose the foramen (William and Abrikossoff, 1911). The two chambers communicate through one or multiple small perforations in the diaphragm usually near its centre or peripherally between a free margin and the atrial wall (Palmer, 1930). The size of the opening may vary from a pin hole (Parsons, 1950) to such a large opening that there is no appreciable obstruction to the 
circulation (Potter and Ranson, 1904 ; Loeffler, 1949). In two cases the septum was complete (Stoeber, 1908; Tannenberg, 1930). The border of the perforation is often thickened and may contain small calcareous deposits (Pedersen and Therkelsen, 1954), or there may be calcification in the wall of the upper chamber (Hartmann, 1955), and areas of endocardial fibro-elastosis in the upper chamber, pulmonary veins, and mitral valve (Doxiadis and Emery, 1953). In all cases but one (Parsons, 1950) the mitral valve was normal. In another case (Patten and Taggart, 1929) the extra chamber was situated anteriorly communicating with both atria.

On the exterior of the atrium a depressed groove may make the line of the septum (Church, 1868) and the pulmonary veins appear dilated and have thick, pale walls (Church, 1868 ; Doxiadis and Emery, 1953 ; Pedersen and Therkelsen, 1954).

Associated defects are not frequent, the most common being patent foramen ovale and atrial septal defect. In 10 of those cases in which it is mentioned the foramen ovale was closed, and in five it was open or there was an atrial septal defect. Abnormal drainage of the pulmonary veins was reported in three cases (Stoeber, 1908; Patten and Taggart, 1929 ; Becu, Tauxe, DuShane, and Edwards, 1955) and Fallot's tetralogy in two (Preisz, 1890).

The effect on the circulation and the ultimate prognosis depends on the degree to which the intra-auricular septum prevents blood flow to the mitral valve, the size and patency of the foramen ovale, and the relationship of the septum to the pulmonary veins and the foramen ovale. In most cases the obstruction to blood flow from the lungs causes pulmonary congestion, pulmonary hypertension, right ventricular hypertrophy, and ultimately systemic congestion.

Those cases in which abnormal cords are present in the left atrium are related to the true cor triatrium (Rolleston, 1896 ; Hepburn, 1896 ; Martin, 1899 ; McNamara, Baker, and Costich, 1947). Most often there is a thin, thread-like cord, but there may be a broad band (Fowler, 1882 ; Griffith, 1903 ; Loeffler, 1949) or a reticular structure (de Vecchi, 1901; Helwig, 1933). The cord is always attached by one end, at or in the neighbourhood of the valve or limbus of the fossa ovalis, while the other end may be attached anywhere in the atrium, at the mitral valve, or even through the left ventricle into the aorta (Goforth, 1926). Such cords or bands have no effect on the circulation and do not produce symptoms or diagnostic problems.

\section{EMBRYOLOGY}

Cor triatrium is a congenital anomaly. Fowler (1882) suggested that it was due to overgrowth of the valve of the foramen ovale, while Martin (1899) thought that it was the result of incomplete disappearance of the wall between the common sinus of the pulmonary veins and the left atrium. Palmer (1930) considered the anomalous septum to be an inversion or direct extension of the wall of the pulmonary vein, so that the postero-superior chamber was the dilated end of the pulmonary vein and the smaller antero-inferior chamber the normal left atrium. Loeffler (1949) came to similar conclusions and called it the " heart with a pulmonary sinus." Parsons (1950), in an extensive review of the literature, concluded that there was developmental arrest in the second month of foetal life causing a defect at the junction between the pulmonary vein and the left atrium. Edwards and others (1951) have suggested the alternative title of "congenital stenosis of the common pulmonary vein," but cor triatrium remains the commonly used term.

\section{Clinical Symptoms and Signs}

Clinically there are two variants. First, those patients in whom there is little or no connexion between the accessory chamber and the left atrium: in them the foramen ovale is usually patent (Doxiadis and Emery, 1953) or there is anomalous pulmonary venous drainage. All die in infancy, usually under 4 months of age, of pulmonary congestion and heart failure. In the second group the septum produces an organic obstruction to pulmonary vein blood flow. The foramen ovale is closed and there are no other anomalies. The most prominent feature of this group is respiratory embarrassment secondary to pulmonary congestion (Parsons, 1950) with secondary pulmonary hypertension and right ventricu- ơ lar failure. Recurrent haemoptyses may occur (Church, 1868; McLester, Bush, and DuBois, 1940 ; Hartmann, 1955). On auscultation, a sys- C tolic murmur has been reported in eight patients, a diastolic murmur in two, and no murmur in 0 four. In this case, a questionable diastolic mur- $\mathbb{\Phi}$ mur was present. In no case has prominence of $\stackrel{\mathcal{P}}{+}$ the mitral first sound or an opening snap been reported. Radiographic findings in 11 patients $\frac{\vec{D}}{\mathbb{D}}$ have revealed either a generalized globular cardiac $\bigcirc$ enlargement or, as in this patient, right ventricu- $\mathbb{\complement}$ lar, left auricular, and pulmonary arterial enlargement with pulmonary congestion (Parsons, 1950 ; 
Hartmann, 1955). Cardiac catheterization (Pedersen and Therkelsen, 1954) is suggestive of mitral disease with pulmonary hypertension, an elevated pulmonary capillary wedge pressure, and a rise on exercise. In our patient, the form of the tracing was consistent with mitral stenosis. Angiocardiography has not been reported; it was attempted in this patient, but auricular fibrillation caused it to be abandoned.

\section{DISCUSSION}

Cor triatrium is a congenital lesion which is particularly amenable to surgical treatment. The majority of the patients reported have succumbed in early childhood, at which time the diagnosis is difficult. The remainder, as in this patient, presented with symptoms of pulmonary congestion, pulmonary hypertension, and ultimately of right heart failure. The clinical picture is indistinguishable from mitral valve disease, but the mitral murmurs may be atypical or absent. The mitral first sound is normal, and there is no opening snap. Radiography, electrocardiography, and cardiac catheterization are of little or no assistance; all are consistent with mitral valve disease.

The operative findings are the most important, and depend upon an awareness of the condition, the external features of the atrium, and digital exploration of that chamber. The condition should be considered in obscure or suspicious cases of pulmonary hypertension associated with a raised pulmonary capillary wedge pressure. The diagnosis is assisted by pressure measurements in the pulmonary veins and left atrium, and they also serve as an indication of the effectiveness of the surgical procedure.

\section{SUMMARY}

The successful operative treatment of a case of cor triatrium in a youth of $\mathbf{1 7}$ years is reported. This is a rare congenital anomaly in which a transverse septum divides the left atrium into two chambers. The anatomy, embryology, symptoms, signs, electrocardiographic, radiographic, and cardiac catheterization findings in this condition are reviewed.

\section{REFERENCES}

Abbott, M. E. (1946). Nelson Loose-Leaf Medicine, Vol. 4, p. 207. Nelson, New York.

Andral, G. (1829). Précis d'Anatomie Pathologique, Vol. 2, p. 313. Gabon, Paris.

Barnes, C. G., and Finlay, H. V. L. (1952). Brit. Heart J., 14, 283.

Becu, L. M., Tauxe, W. N., DuShane, J. W., and Edwards, J. E. (1955). A.M.A. Arch. Path., 59, 463.

Church, W. S. (1868). Trans. path. Soc. Lond., 19, 188.

Doxiadis, S. A., and Emery, J. L. (1953). J. Pediat., 42, 87.

Edwards, J. E., DuShane, J. W., Alcott, D. L., and Burchell, H. B. (1951). A.M.A. Arch. Path., 51, 446.

Fowler, J. K. (1882). Trans. path. Soc. Lond., 33, 77.

Goforth, J. L. (1926). J. Amer. med. Ass., 86, 1612.

Griffith, T. W. (1903). J. Anat. (Lond.), 37, 255.

Hartmann, H. A. (1955). A.M.A. Arch. Path., 59, 706.

Helwig, F. C. (1933). Arch. Path. (Chicago), 15, 8.

Hepburn, D. (1896). J. Anat. (Lond.), 30, 582.

Loeffler, E. (1949). Arch. Path. (Chicago), 48, 371.

McLester, J. B., Bush, J. D., and DuBois, I. S. (1940). Amer. Heart $J ., 19,492$.

McNamara, W. L., Baker, L. A., and Costich, K. (1947). Ibid., 34, 288.

Martin, S. (1899). [Proc. Anat. Soc., July, 1899, p. xxxi.] J. Anat. (Lond.).

Palmer, G. A. (1930). Amer. Heart J., 6, 230.

Parsons, C. G. (1950). Brit. Heart J., 12, 327.

Patten, B. M., and Taggart, W. B. (1929). Arch. Path. (Chicago), 8, 894.

Pedersen, A., and Therkelsen, F. (1954). Amer Heart J., 47, 676.

Potter, P., and Ranson, S. W. (1904). J. Anat. (Lond.), 39, 69.

Preisz, H. (1890). Beitr. path. Anat., 7, 272.

Rolleston, H. D. (1896). J. Anat. (Lond.), 30, v.

Stoeber, H. (1908). Virchows Arch. path. Anat., 193, 252.

Tannenberg, J. (1930). Klin. Wschr., 9, 1473.

Vecchi, B. de (1901). Anat. Anz., 20, 374.

William, N., and Abrikossoff, A. (1911). Virchows Arch. path. Anat., 203, 404. 